ORIGINAL ARTICLE

\title{
Physique traits of lightweight rowers and their relationship to competitive success
}

\author{
G J Slater, A J Rice, I Mujika, A G Hahn, K Sharpe, D G Jenkins
}

Br J Sports Med 2005;39:736-741. doi: 10.1136/bjsm.2004.015990

See end of article for authors' affiliations

.....................

Correspondence to:

Gary J Slater, Singapore

Sports Council, 15

Stadium Road,' National

Stadium, Singapore

397718;

Gary_Slater@ssc.gov.sg

Accepted 8 February 2005

\begin{abstract}
Objectives: Physique traits and their relationship to competitive success were assessed amongst lightweight rowers competing at the 2003 Australian Rowing Championships.

Methods: Full anthropometric profiles were collected from 107 lightweight rowers ( $n=65$ males, $n=45$ females) competing in the Under 23 and Open age categories. Performance assessments were obtained for 66 of these rowers based on results in the single sculls events. The relationship between physique traits and competitive success was then determined.

Results: Lower body fat (heat time estimate $-8.4 \mathrm{~s} \mathrm{~kg}^{-1}, \mathrm{p}<0.01$ ), greater total body mass (heat time estimate $-4.4 \mathrm{~s} \mathrm{~kg}^{-1}, \mathrm{p}=0.03$ ), and muscle mass (heat time estimate $-10.2 \mathrm{~s} \mathrm{~kg}^{-1}, \mathrm{p}<0.01$ ) were associated with faster $2000 \mathrm{~m}$ heat times.

Conclusions: The more successful lightweight rowers were those who had lower body fat and greater total muscle mass.
\end{abstract}

A relationship between competitive success and physique traits has been identified in an array of sports, including football codes, ${ }^{1}$ aesthetically judged sports, ${ }^{2}$ swimming, ${ }^{3}$ track and field events, ${ }^{4}$ and skiing, ${ }^{5}$ plus lightweight ${ }^{6}$ and heavyweight rowing. ${ }^{7}$ The specific physique traits associated with competitive success vary with the sport. For athletes participating in aesthetically judged sports, maintenance of low body fat levels is associated with positive outcomes. $^{289}$ A similar relationship exists in sports where frontal surface area, power to weight ratio, and/or thermoregulation are important. ${ }^{10}$ However, in sports demanding high force production, muscle mass may be more closely associated with performance outcomes. ${ }^{13}$

Amongst both junior ${ }^{11-13}$ and senior heavyweight rowers, ${ }^{14}{ }^{15}$ performance is positively correlated with muscle mass and/or absolute body mass. Despite the body mass limits imposed on lightweight rowers (maximal weights of $59 \mathrm{~kg}$ (crew average $57 \mathrm{~kg}$ ) and $72.5 \mathrm{~kg}$ (crew average $70 \mathrm{~kg}$ ) for females and males, respectively), muscle mass remains a determinant of competitive success. ${ }^{6}$

Comparisons between medallists and non-medallists at world championships suggest that successful lightweight rowers are more mesomorphic, less endomorphic, and tend to have a short sitting height plus longer upper and lower extremities, ${ }^{6}$ the latter being consistent with findings in heavyweight rowers and offering greater biomechanical efficiency. ${ }^{7}$ However, these conclusions are derived from data collected during the 1980s, soon after the introduction of the lightweight category to international competition. It is unknown if the relationships still exist given the much higher profile and more competitive environment of lightweight rowing. Thus, our understanding of the association between physique traits and competitive success among lightweight rowers has not been addressed for several decades despite the potential for morphological optimisation during this time, as has occurred within the heavyweight division. ${ }^{10}$ The confirmation of unique physical characteristics amongst successful lightweight rowers would be invaluable for future talent identification and development programs.

The primary aim of the present study was to examine the relationship between physique traits and competitive success among lightweight rowers. We also sought to quantify the effect of small differences in muscle mass and fat mass on competitive performance. It was hypothesised that larger, more muscular athletes would be more successful.

\section{METHODS}

\section{Subjects}

A total of 107 lightweight rowers competing at the 2003 Australian Rowing Championships in either the Under 23 (U23; $\mathrm{n}=35$ males, $\mathrm{n}=28$ females) or Open age (OPEN; $\mathrm{n}=27$ males, $\mathrm{n}=17$ females) divisions volunteered to participate in this investigation. Volunteers were fully informed of the nature and possible risks of the investigation before giving their written informed consent. The investigation was approved by the Human Research Ethics Committee of the Australian Institute of Sport.

\section{Physique}

Volunteers undertook a single physique assessment during the regatta; the timing of assessments was not standardised. All subjects were landmarked by an anthropometrist holding level III accreditation from the International Society for the Advancement of Kinanthropometry (ISAK). Full anthropometric profiles, including body mass, skinfolds at 8 sites, 11 girths, 12 lengths, and 6 breadths were measured by ISAK accredited level II anthropometrists with technical errors of measurement of $<3 \%$ for skinfolds and $\leqslant 1 \%$ for all other measures.

Body mass was assessed in minimal clothing on a calibrated digital scale with a precision of $\pm 0.02 \mathrm{~kg}$ (A \& D, Tokyo, Japan). Sitting height and stretch stature were measured using a portable stadiometer (Seca, Hamburg, Germany) with a precision of $\pm 1 \mathrm{~mm}$. Skinfolds were assessed using Harpenden callipers (British Indicators, St Albans, Hertfordshire, UK). Girth measurements were made using a flexible steel tape (Lufkin W 606 PM, Cooper Industries, Lexington, SC). Several girths were corrected for skinfolds, as described elsewhere. ${ }^{16}$ Upper body limb lengths

Abbreviations: ISAK, International Society for the Advancement of Kinanthropometry; NATA, National Association of Testing Authorities; SAM, somatotype attitudinal mean 
A

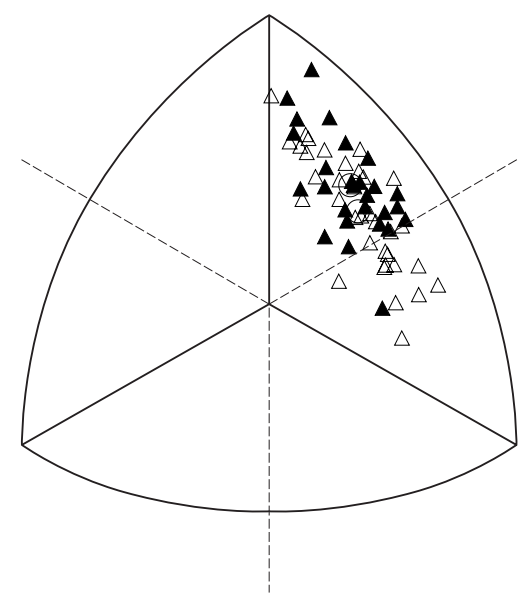

B

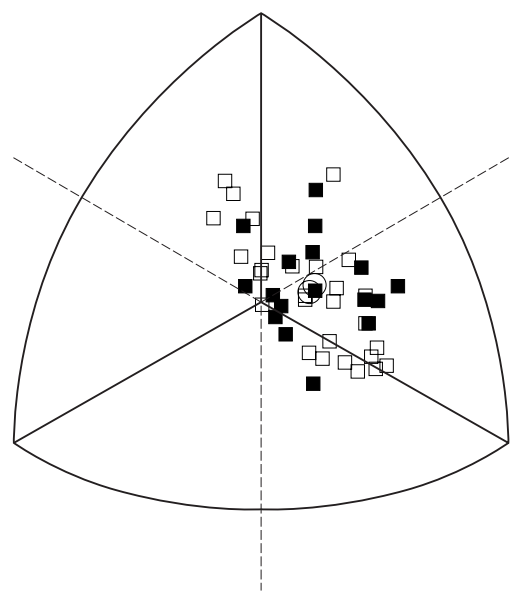

Figure 1 Somatocharts of male (a) and female (b) somatotype distributions for both U23 (unfilled icons) and OPEN (filled icons) athletes. Circles represent the mean somatotype for each age category.

were measured with a modified steel tape adapted with a segmometer (Rosscraft, Surrey, BC, Canada); all other lengths were assessed using a large sliding calliper (British Indicators). The majority of breadths were also measured with the large sliding calliper; biepicondylar breadths were measured with Vernier callipers (Holtain, Crosswell, Dyfed, UK). All anthropometric equipment was calibrated prior to the assessment period, with additional checks against National Association of Testing Authorities (NATA) certified calibration weights and rods.
All measurements were made on the right side of the body using techniques previously described. ${ }^{17}$ The full anthropometric profile was undertaken in duplicate. If the difference between duplicate measures exceeded $5 \%$ for skinfolds or $1 \%$ for any other parameter, a third measurement was taken but only after the full profile had been completed in duplicate. The mean of duplicate or median of triplicate anthropometric variables was used for all subsequent analyses.

Anthropometric variables were used to create a four-way fractionation of body mass, partitioning total body mass into

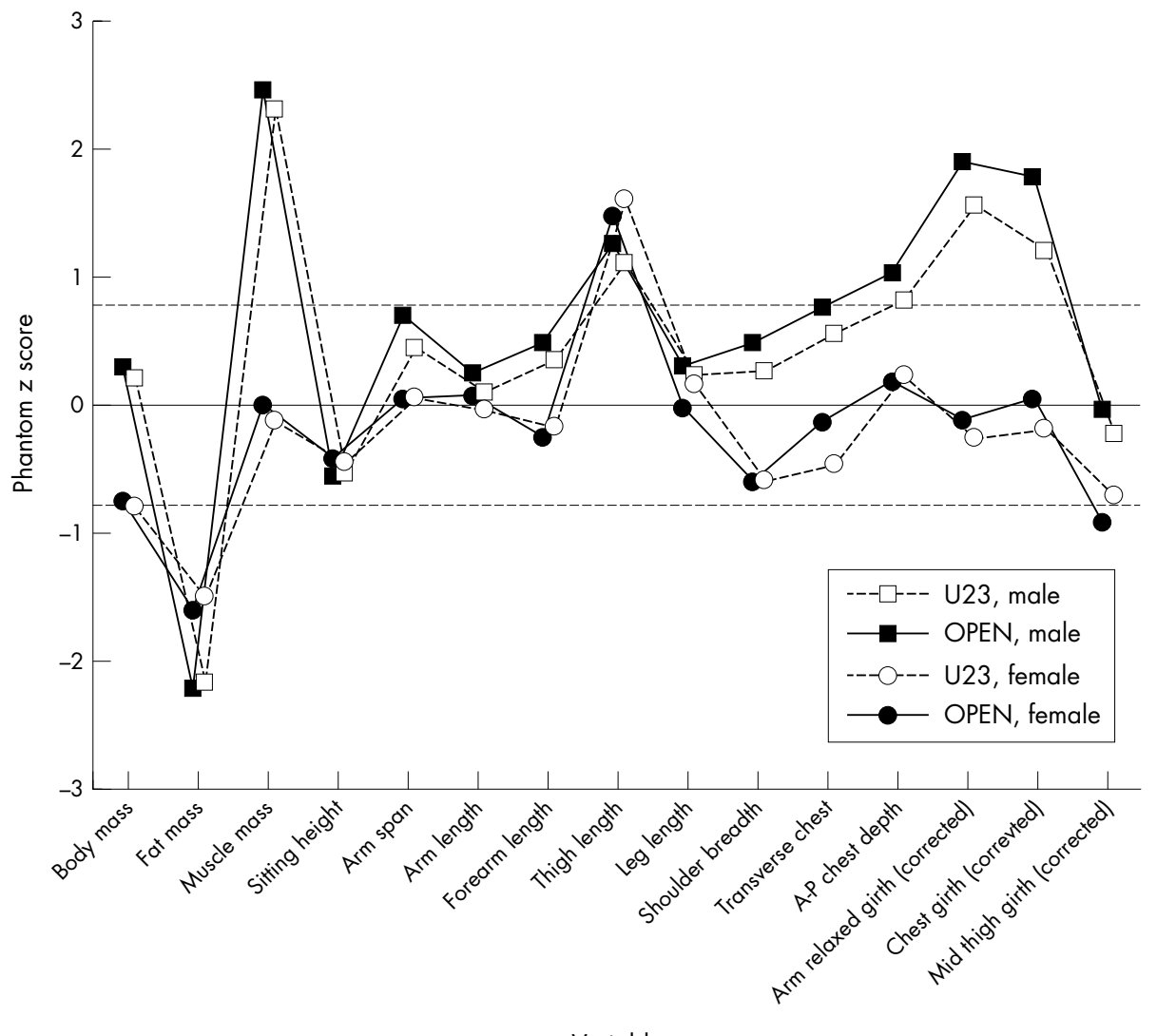

Variable

Figure 2 Relative body size of lightweight rowers competing in the 2003 Australian Rowing Championships, as indicated by phantom z scores. The dotted lines represent an effect size of 0.8 , beyond which large deviations from proportionality (relative to stature) are evident. 
Table la Physique traits of male rowers competing in the 2003 Australian Rowing Championships

\begin{tabular}{|c|c|c|c|c|}
\hline \multirow[b]{2}{*}{ Variable } & \multicolumn{2}{|c|}{ Male U23, $n=35$} & \multicolumn{2}{|c|}{ Male OPEN, $n=27$} \\
\hline & Mean & SD & Mean & SD \\
\hline Body mass (kg) & 70.6 & 1.9 & 71.2 & 1.1 \\
\hline Sum of eight skinfolds (mm) & 44.5 & 7.1 & 42.7 & 7.2 \\
\hline \multicolumn{5}{|l|}{ Lengths $(\mathrm{cm})$} \\
\hline Height & 181.6 & 5.2 & 180.7 & 3.9 \\
\hline Sitting height & 93.4 & 2.6 & 92.7 & 2.9 \\
\hline Arm span & 187.2 & 6.6 & 188.4 & 3.8 \\
\hline Arm length & 34.9 & 1.5 & 35.0 & 1.0 \\
\hline Forearm length & 26.7 & 1.2 & 26.8 & 0.7 \\
\hline Thigh length & 47.0 & 2.1 & 47.2 & 1.7 \\
\hline Leg length & 48.5 & 1.8 & 48.3 & 1.3 \\
\hline Sitting height/stature (\%) & 51.4 & 0.8 & 51.3 & 0.8 \\
\hline Arm length/stature (\%) & 45.0 & 1.0 & 45.4 & 1.0 \\
\hline \multicolumn{5}{|l|}{ Breadths $(\mathrm{cm})$} \\
\hline Shoulder breadth & 41.1 & 1.4 & 41.4 & 0.9 \\
\hline Transverse chest & 30.8 & 1.2 & 31.0 & 0.9 \\
\hline A-P chest depth & 19.9 & 1.0 & 20.1 & 0.9 \\
\hline Humerus breadth & 7.2 & 0.3 & 7.2 & 0.3 \\
\hline Femur breadth & 9.9 & 0.3 & 10.0 & 0.3 \\
\hline \multicolumn{5}{|l|}{ Girths (cm) } \\
\hline Arm relaxed corrected & 26.7 & 1.4 & 27.2 & 1.4 \\
\hline Arm flexed and tensed & 31.8 & 1.3 & $32.6^{*}$ & 1.3 \\
\hline Forearm & 27.7 & 0.8 & 27.8 & 0.7 \\
\hline Chest corrected & 94.1 & 2.8 & $96.6^{*}$ & 2.9 \\
\hline Waist & 75.1 & 2.8 & 76.3 & 2.5 \\
\hline Hip & 92.7 & 2.0 & 92.8 & 1.9 \\
\hline Mid thigh corrected & 49.5 & 2.0 & 50.0 & 1.6 \\
\hline Calf corrected & 34.8 & 1.4 & 34.7 & 1.3 \\
\hline \multicolumn{5}{|l|}{ Estimated mass (kg) } \\
\hline Fat & 5.4 & 0.7 & 5.2 & 0.7 \\
\hline Residual & 20.1 & 1.3 & 20.3 & 1.0 \\
\hline Bone & 12.2 & 0.9 & 12.4 & 1.4 \\
\hline Muscle & 34.5 & 1.2 & 34.9 & 1.2 \\
\hline \multicolumn{5}{|l|}{ Somatotype } \\
\hline Endomorphy & 1.4 & 0.3 & 1.4 & 0.4 \\
\hline Mesomorphy & 4.4 & 0.8 & 4.8 & 0.8 \\
\hline Ectomorphy & 3.6 & 0.8 & 3.4 & 0.6 \\
\hline Attitudinal mean (SAM) & 1.05 & - & 0.88 & - \\
\hline
\end{tabular}

*Significantly different to U23 $(\mathrm{p}<0.05)$.

No analysis was undertaken between genders. Data are presented as means and SD.

fat mass, muscle mass, bone, and residual mass using the phantom model, ${ }^{16}$ the validity of which has been addressed previously. ${ }^{18}$ The somatotype and somatotype attitudinal means (SAM) were calculated using the method of Carter. ${ }^{19}$ The relative magnitude of a physical characteristic with respect to stature was assessed via the calculation of phantom z scores. ${ }^{20}$

\section{Performance}

The impact of an intervention on rowing performance is generally inferred via simulated racing on an ergometer in a controlled laboratory environment. However, it has been argued that a $2000 \mathrm{~m}$ time trial on an ergometer may not reflect the metabolic demands of on-water rowing, ${ }^{21}$ especially in smaller boats where it takes significantly less time to complete the effort on an ergometer than on water. ${ }^{15}$ With this in mind, performance was assessed via heat times and overall placing at the 2003 Australian Rowing Championships. Only race results of athletes competing in single sculls were used as sweep events comprise two or more athletes (and thus two or more physiques) in a single boat. For the purpose of this investigation, athletes who qualified for " $\mathrm{A}$ " finals were considered successful.

\section{Statistical analysis}

Associations between physique traits and heat times (plus overall placing) were assessed by an analysis of covariance (ANCOVA) with heat times (or final placing) as the
Table $1 \mathrm{~b}$ Physique traits of female rowers competing in the 2003 Australian Rowing Championships

\begin{tabular}{|c|c|c|c|c|}
\hline \multirow[b]{2}{*}{ Variable } & \multicolumn{2}{|c|}{ Female U23, $n=28$} & \multicolumn{2}{|c|}{ Female OPEN, $n=17$} \\
\hline & Mean & SD & Mean & SD \\
\hline Body mass $(\mathrm{kg})$ & 57.4 & 1.6 & 57.9 & 1.1 \\
\hline Sum of eight skinfolds (mm) & 73.6 & 15.5 & 68.5 & 17.1 \\
\hline \multicolumn{5}{|c|}{ Lengths $(\mathrm{cm})$} \\
\hline Height & 170.0 & 5.3 & 170.3 & 3.5 \\
\hline Sitting height & 87.8 & 3.2 & 88.0 & 1.8 \\
\hline Arm span & 172.2 & 5.3 & 172.7 & 4.5 \\
\hline Arm length & 32.4 & 1.8 & 32.6 & 1.1 \\
\hline Forearm length & 24.3 & 1.1 & 24.2 & 0.9 \\
\hline Thigh length & 45.3 & 2.1 & 45.1 & 1.5 \\
\hline Leg length & 45.2 & 1.9 & 44.8 & 1.3 \\
\hline Sitting height/stature (\%) & 51.6 & 1.2 & 51.7 & 0.8 \\
\hline Arm length/stature (\%) & 44.4 & 1.2 & 44.4 & 0.8 \\
\hline \multicolumn{5}{|l|}{ Breadths $(\mathrm{cm})$} \\
\hline Shoulder breadth & 36.8 & 1.4 & 36.9 & 1.3 \\
\hline Transverse chest & 27.0 & 1.0 & $27.7^{*}$ & 1.0 \\
\hline A-P chest depth & 17.8 & 1.0 & 17.7 & 1.3 \\
\hline Humerus breadth & 6.3 & 0.2 & 6.3 & 0.2 \\
\hline Femur breadth & 9.0 & 0.3 & 9.0 & 0.2 \\
\hline \multicolumn{5}{|l|}{ Girths $(\mathrm{cm})$} \\
\hline Arm relaxed corrected & 21.5 & 1.0 & 21.8 & 0.9 \\
\hline Arm flexed and tensed & 27.2 & 1.1 & 27.6 & 0.9 \\
\hline Forearm & 24.0 & 0.7 & 23.9 & 0.7 \\
\hline Chest corrected & 81.4 & 2.6 & 82.7 & 2.1 \\
\hline Waist & 66.0 & 2.3 & $67.9^{*}$ & 1.6 \\
\hline Hip & 91.7 & 2.2 & 91.5 & 1.8 \\
\hline Mid thigh corrected & 44.6 & 2.0 & 44.1 & 1.7 \\
\hline Calf corrected & 30.8 & 2.1 & 31.4 & 2.6 \\
\hline \multicolumn{5}{|l|}{ Estimated mass $(\mathrm{kg})$} \\
\hline Fat & 7.1 & 1.3 & 6.8 & 1.4 \\
\hline Residual & 15.5 & 0.8 & 15.9 & 0.9 \\
\hline Bone & 9.0 & 0.5 & 8.8 & 0.9 \\
\hline Muscle & 25.1 & 1.3 & 25.5 & 1.3 \\
\hline \multicolumn{5}{|l|}{ Somatotype } \\
\hline Endomorphy & 2.5 & 0.6 & 2.4 & 0.7 \\
\hline Mesomorphy & 3.3 & 0.9 & 3.3 & 0.7 \\
\hline Ectomorphy & 3.7 & 0.9 & 3.7 & 0.6 \\
\hline Attitudinal mean (SAM) & 1.25 & - & 1.06 & - \\
\hline
\end{tabular}

*Significantly different to U23 $(\mathrm{p}<0.05)$.

No analysis was undertaken between genders. Data are presented as means and SD.

dependent variable, gender and category (U23 and OPEN) as categorical predictors, and individual physique traits as a covariate. Differences between athlete categories and variance in physical characteristics between successful (that is, " $\mathrm{A}$ " finalists) and less successful athletes (non-finalists) were assessed using a one way analysis of variance (ANOVA). When a significant main effect was observed, a NewmanKeul's post hoc test was used to locate significant differences between means. Strength of deviations from the phantom were evaluated using $\mathrm{z}$ scores as an index of effect size. Operationally defined, a $\mathrm{z}$ score $\geqslant 0.20$ is a small effect, a $\mathrm{z}$ score $\geqslant 0.50$ is a medium effect, and a $\mathrm{z}$ score $\geqslant 0.80$ is a large effect. ${ }^{22}$ All statistical analyses were undertaken using Statistica software for Windows (version 6.0, StatSoft, Tulsa, OK). Significance was accepted at $\mathrm{p}<0.05$ and all data are presented as the mean (standard deviation, SD).

\section{RESULTS}

From the 132 lightweight rowers who competed at the 2003 Australian Rowing Championships and volunteered to participate in this investigation, 107 full anthropometric profiles and 66 single scull regatta results were collected and submitted for analysis.

\section{Physique}

Table 1 ( $a$ and b) shows a summary of the anthropometric data. Few differences were evident between age groups. However, OPEN females possessed larger transverse chest 
breadths $(p=0.04)$ and waist $(p<0.01)$ girths compared to U23 females, while OPEN males had larger arm flexed and tensed $(p=0.01)$ plus skinfold corrected chest $(p<0.01)$ girths. The differences between the sum of the fractionated masses and measured body mass were small, fractionated mass being within $0.8 \%$ (SD 3.5\%) of measured mass. Somatocharts of male and female somatotype distributions are displayed in fig 1 .

Lower body fat and higher levels of muscle mass (and total mass), as estimated by anthropometric fractionation, were associated with faster heat times (table 2) and superior overall regatta placing amongst athletes. The same trends persisted when a comparison was made between physique traits of athletes who qualified for " $\mathrm{A}$ " finals and those that did not. Successful female athletes tended to have lower body fat levels than their less successful competitors, both in the U23 ("A" finalist 6.3 (SD 1.7) kg, non-finalist 7.5 (SD 1.0) $\mathrm{kg} ; \mathrm{p}=0.06$ ) and OPEN categories ("A" finalist 6.2 (SD 1.3 ) kg, non-finalist 8.1 (SD 0.6) kg; $\mathrm{p}=0.02$ ). Similarly, more successful OPEN category female athletes had lower relative endomorphy ratings ("A" finalist 2.1 (SD 0.6) kg, non-finalist 2.9 (SD 0.3) kg; $\mathrm{p}=0.02$ ). Successful oarswomen tended to possess more muscle mass, the effect stronger within the U23 category ("A" finalist 26.0 (SD 1.2) $\mathrm{kg}$, non-finalist 25.1 (SD 0.90) kg; p=0.08) than the OPEN category ("A" finalist 25.6 (SD 1.1) kg, non-finalist 24.5 (SD 1.0) kg; $\mathrm{p}=0.14$ ). Similar trends were evident amongst oarsmen.

Relative body size (that is, relative to stature) or proportionality characteristics of oarsmen and oarswomen are displayed in fig 2. Proportionally low body fat levels and longer thigh lengths were common to all groups of rowers. Relative body size was similar between younger and more senior athletes. However, gender differences were evident. Males possessed proportionally high muscle mass with associated large skinfold corrected girths, especially on the upper body. This effect was not evident amongst oarswomen although they were relatively lighter.

\section{DISCUSSION}

The primary finding of the present investigation is that amongst competitive lightweight rowers, physique traits are related to performance outcomes. Successful lightweight rowers possess more muscle mass and less body fat than their less successful counterparts, a finding similar to that previously reported amongst elite lightweight oarsmen. ${ }^{6}$

Anthropometric traits of athletes competing in the lightweight division at the 2003 Australian Rowing Championships were similar to those reported amongst lightweight rowers competing at the 1985 World Championships $^{6}$ and the 2000 Sydney Olympic Games. ${ }^{23}$ Accordingly, it appears that the somatotypes of lightweight male and female rowers have changed little in the last two decades (fig 3). ${ }^{6324}$ Oarsmen remain predominantly ectomorphic-mesomorphs, while oarswomen were mesomorphicectomorphs. Physique traits differed little between athletes competing in the U23 and OPEN categories, suggesting any performance variance between these groups was related to factors other than physique.

A short sitting height (relative to stature) and longer limb lengths are characteristic of both lightweight ${ }^{24}$ and heavyweight rowers, ${ }^{14}$ conferring greater biomechanical efficiency. ${ }^{10}$ These structural traits were evident amongst athletes in the present investigation, as inferred via small sitting height to stature ratios and large arm length to stature ratios. ${ }^{10}$ In spite of this, competitive success was not strongly associated with these physique traits. Perhaps this is because of the homogeneity of physique traits amongst the present lightweight rowers, as indicated by low SAM scores, a
Table 2 Association between physique traits and heat times among lightweight single scullers $(n=66)$

\begin{tabular}{|c|c|c|}
\hline Variable & $\begin{array}{l}\text { Parameter } \\
\text { estimate (s) }\end{array}$ & $\mathbf{p}$ \\
\hline Body mass $(\mathrm{kg})$ & -4.4 & 0.03 \\
\hline Sum of eight skinfolds (mm) & 0.9 & $<0.01$ \\
\hline \multicolumn{3}{|l|}{ Lengths $(\mathrm{cm})$} \\
\hline Height & -0.6 & 0.36 \\
\hline Sitting height & -0.5 & 0.69 \\
\hline Arm span & -0.6 & 0.33 \\
\hline Arm length & -2.2 & 0.28 \\
\hline Forearm length & -1.7 & 0.59 \\
\hline Thigh length & -2.0 & 0.18 \\
\hline Leg length & -1.5 & 0.40 \\
\hline Sitting height/stature (\%) & 2.4 & 0.46 \\
\hline Arm length/stature (\%) & -1.7 & 0.65 \\
\hline \multicolumn{3}{|l|}{ Breadths $(\mathrm{cm})$} \\
\hline Shoulder breadth & 0.7 & 0.79 \\
\hline Transverse chest & -5.0 & 0.14 \\
\hline A-P chest depth & -1.9 & 0.55 \\
\hline Humerus breadth & -12.1 & 0.41 \\
\hline Femur breadth & -4.3 & 0.69 \\
\hline \multicolumn{3}{|l|}{ Girths $(\mathrm{cm})$} \\
\hline Arm relaxed corrected & -4.1 & 0.12 \\
\hline Arm flexed and tensed & -1.4 & 0.62 \\
\hline Forearm & -1.4 & 0.77 \\
\hline Chest corrected & -4.1 & $<0.01$ \\
\hline Waist & -2.5 & 0.09 \\
\hline Hip & 0.8 & 0.60 \\
\hline Mid thigh corrected & -3.9 & 0.01 \\
\hline Calf corrected & -2.3 & 0.16 \\
\hline \multicolumn{3}{|l|}{ Estimated mass $(\mathrm{kg})$} \\
\hline Fat & 8.4 & $<0.01$ \\
\hline Residual & -3.7 & 0.23 \\
\hline Bone & -0.2 & 0.96 \\
\hline Muscle & -10.2 & $<0.01$ \\
\hline \multicolumn{3}{|l|}{ Somatotype } \\
\hline Endomorphy & 19.4 & $<0.01$ \\
\hline Mesomorphy & 0.1 & 0.98 \\
\hline Ectomorphy & -1.4 & 0.71 \\
\hline
\end{tabular}

The impact of these physique traits on heat times is estimated (that is, parameter estimate); negative values indicate an increase in a specified physique trait (per unit, for example, for $\mathrm{kg}$ in fat and muscle) will result in a decrease in heat time. Data have been collapsed across gender and age group. Sweep oarsmen have been omitted from analysis.

measure of the average dispersion of individual somatotypes from the group mean. ${ }^{19}$

In view of the known influence of physiological variables and skill levels on rowing performance, ${ }^{25}$ the identification of very strong relationships between a wide array of anthropometric characteristics alone and competitive success would be surprising, especially amongst a homogeneous population of lightweight rowers. Indeed, strong associations were only evident for estimates of fat mass and muscle mass, parameters that were derived from an array of measured physique traits, including skinfolds and girths. ${ }^{16}$ The strength of association between body composition and performance confirms that lightweight rowers should prioritise the manipulation of not only fat mass but also muscle mass as they prepare to achieve specified body mass limits for upcoming regattas.

It is important to acknowledge that any association between physique traits and competitive success may have been influenced by acute body mass management strategies undertaken by volunteers prior to racing, the performance implications of which can be substantial if aggressive recovery strategies are not enforced following weigh in. ${ }^{26}$ Indices of hydration status confirmed the majority of volunteers were hypohydrated at the time of weigh in. Consequently, the strength of association between physique traits and performance reported in the present investigation could be considered conservative. 

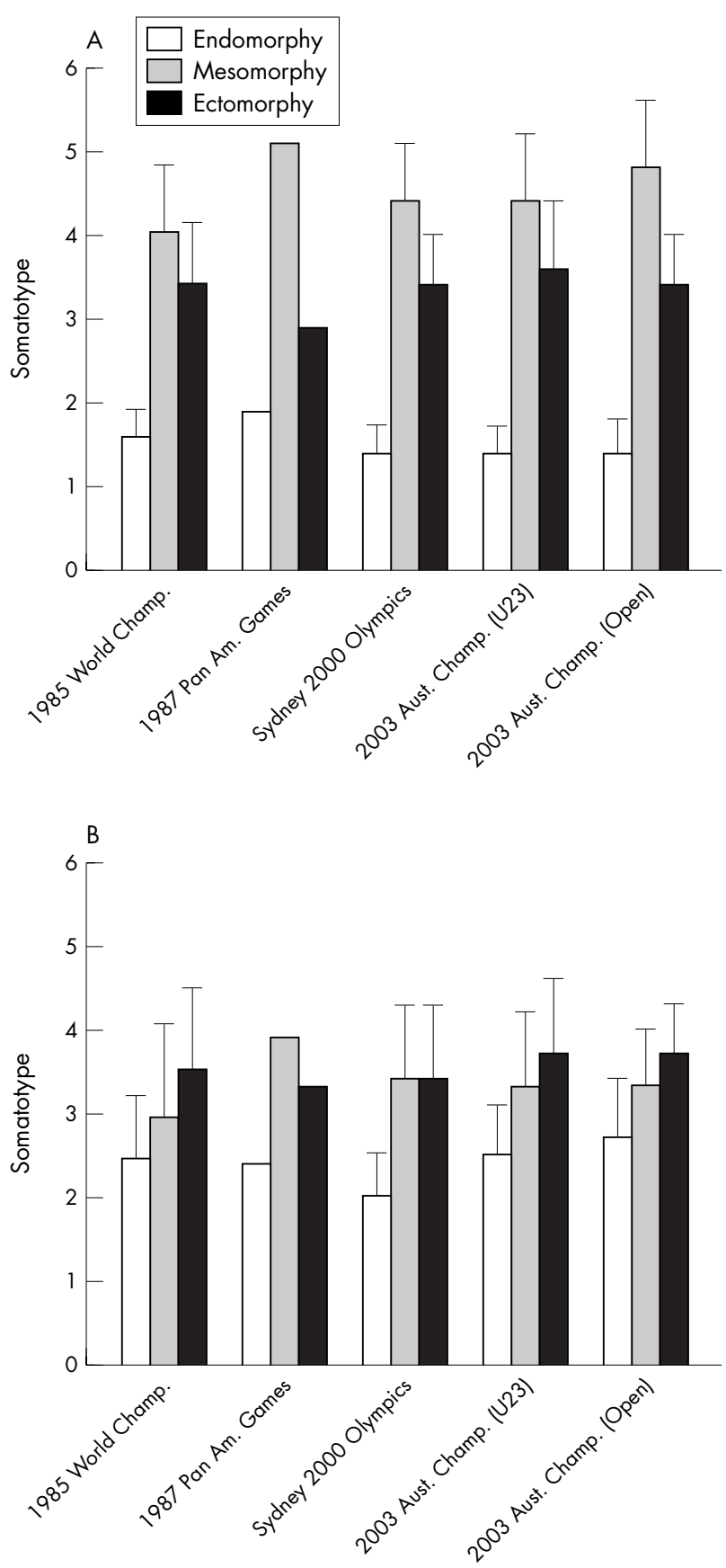

Figure 3 Somatotype of male (a) and female (b) lightweight rowers reported over the last two decades and competing in the 1985 World Championships, ${ }^{6} 1987$ Pan American Games, ${ }^{24}$ Sydney 2000 Olympics, ${ }^{23}$ and U23 and OPEN categories of the 2003 Australian Championships (present investigation). Values are means (SD).

As hydration status has a negligible impact on results of anthropometric profiling, ${ }^{27}$ anthropometry was considered the most appropriate tool for assessing physique traits in the present investigation. A range of other techniques are available for estimating body composition including radiographic (computer tomography, magnetic resonance imaging, dual energy $x$ ray absorptiometry), metabolic (creatinine, 3-methylhistidine), nuclear (total body potassium, total body nitrogen), and bioelectrical impedance techniques. ${ }^{28}$ However, none of these techniques provide accurate estimates of lever lengths, qualities that influence the biomechanical efficiency of the rowing stroke and thus
What is already known about this topic

Successful lightweight rowers are tall with long upper and lower extremities and short sitting height. They are also more muscular, with lower body fat levels than their less successful counterparts. However, this information comes from work collected soon after the introduction of the lightweight category to international competition (1985).

\section{What this study adds}

This update has confirmed that successful lightweight rowers possess more muscle mass and less body fat than their less successful counterparts. Physique traits of lightweight rowers have remained stable for the past two decades. Estimates of the impact of variance in physique traits on performance are provided.

performance. ${ }^{10}$ Furthermore, results from many of these physique assessment techniques are influenced by hydration status, ${ }^{29}{ }^{30}$ rendering them inappropriate during a regatta when athletes are likely to present in a hypohydrated state.

Anthropometric fractionation of body mass was used to obtain data on estimates of skeletal, residual, fat, and muscle masses. ${ }^{16}$ As was also evident from the work of Withers and associates, ${ }^{18}$ absolute differences between measured body mass and that resulting from the sum of the four fractionated masses were very small. As each of the four estimated masses is derived independently of body mass, the degree to which their total approximates the measured mass has been used as an internal validity criterion. ${ }^{18}$

Heat times were chosen as an index of performance so as to maximise the total subject pool available for analysis (that is, only the top eight athletes in each category competed in the final). Furthermore, the inclusion of heat times allowed an estimate (in seconds) of the impact of variation in physique traits on $2000 \mathrm{~m}$ race times. As heats within a particular category follow in succession, the impact of variance in environmental conditions on race times should be minimised. Identical outcomes were observed when overall performance rank was substituted in the analysis for heat times, confirming that factors such as environmental conditions and physical exertion applied in a heat had little, if any, impact on outcomes.

In summary, the present investigation has confirmed that the physique traits of lightweight rowers have remained stable for the past two decades and continue to be a determinant of competitive success. Leaner athletes with greater total muscle mass are more successful.

\section{ACKNOWLEDGEMENTS}

The authors would like to thank all lightweight rowers competing in the 2003 Australian Rowing Championships for their cooperation. Special thanks also to Hamilton Lee, Marc Quod, Camilla Mather, Roberto Solano, Michelle Edwards, and Sally Wright from the Department of Physiology, Australian Institute of Sport, for their assistance with data collection.

\section{Authors' affiliations}

G J Slater, A J Rice, I Mujika, A G Hahn, Australian Institute of Sport, Belconnen, Canberra, ACT 2616, Australia

K Sharpe, Department of Mathematics and Statistics, University of Melbourne, Melbourne, VIC, Australia 
D G Jenkins, School of Human Movement Studies, University of Queensland, St Lucia, QLD 4072, Australia

This investigation was supported by a grant from the Australian Institute of Sport

Competing interests: none declared

\section{REFERENCES}

1 Olds $\mathrm{T}$. The evolution of physique in male rugby union players in the twentieth century. J Sports Sci 2001; 19:253-62.

2 Claessens AL, Lefevre J, Beunen G, et al. The contribution of anthropometric characteristics to performance scores in elite female gymnasts. J Sports Med Phys Fitness 1999;39:355-60.

3 Siders WA, Lukaski HC, Bolonchuk WW. Relationships among swimming performance, body composition and somatotype in competitive collegiate swimmers. J Sports Med Phys Fitness 1993:33:166-71.

4 Claessens AL, Hlatky S, Lefevre J, et al. The role of anthropometric characteristics in modern pentathlon performance in female athletes. I Sports Sci 1994; 12:391-401

5 White AT, Johnson SC. Physiological comparison of international, national and regional alpine skiers. Int J Sports Med 1991;12:374-8.

6 Rodriguez FA. Physical structure of international lightweight rowers. In: Reilly T, Watkins J, Borms J, eds. Kinanthropometry III. London: E and FN Spon, 1986:255-61.

7 Shephard RJ. Science and medicine of rowing: a review. J Sports Sci 1998;16:603-20.

8 Fry AC, Ryan AJ, Schwab RJ, et al. Anthropometric characteristics as discriminators of body-building success. J Sports Sci 1991;9:23-32.

9 Faria IE, Faria EW. Relationship of the anthropometric and physical characteristics of male junior gymnasts to performance. J Sports Med Phys Fitness 1989;29:369-78.

10 Norton K, Olds T, Olive S, et al. Anthropometry and sports performance. In: Norton K, Olds T, eds. Anthropometrica. Sydney: University of New South Wales Press, 1996:287-364.

11 Bourgois J, Claessens AL, Janssens M, et al. Anthropometric characteristics of elite female junior rowers. J Sports Sci 2001;19:195-202.

12 Bourgois J, Claessens AL, Vrijens J, et al. Anthropometric characteristics of elite male junior rowers. Br J Sports Med 2000;34:213-6, discussion 6-7.

13 Russell AP, Le Rossignol PF, Sparrow WA. Prediction of elite schoolboy $2000 \mathrm{~m}$ rowing ergometer performance from metabolic, anthropometric and strength variables. J Sports Sci 1998;16:749-54.

$14 \mathrm{Hahn}$ A. Identification and selection of talent in Australian rowing. EXCEL 1990;6:5-11

15 Jurimae J, Maestu J, Jurimae T, et al. Prediction of rowing performance on single sculls from metabolic and anthropometric variables. J Hum Mov Stud 2000;38:123-36.
16 Drinkwater DT, Ross WD. Anthropometric fractionation of body mass. In: Ostyn M, Beunen G, Simons J, eds. Kinanthropometry II. Vol IX. Baltimore: University Park Press, 1980:178-89.

17 Norton K, Whittingham NO, Carter L, et al. Measurement techniques in anthropometry. In: Norton KI, Olds T, eds. Anthropometrica. Sydney: University of New South Wales Press, 1996:25-76.

18 Withers RT, Craig NP, Ball CT, et al. The Drinkwater-Ross anthropometric fractionation of body mass: comparison with measured body mass and densitometrically estimated fat and fat-free masses. J Sports Sci 1991;9:299-311.

19 Carter L. Somatotyping. In: Norton K, Olds T, eds. Anthropometrica. Sydney: University of New South Wales Press, 1996:147-70.

20 Ross WD, Marfell-Jones M. Kinanthropometry. In: MacDougall JD Wenger HA, Green HJ, eds. Physiological testing of the highperformance athlete, 2nd ed. Champaign, IL: Human Kinetics, 1991:223-308

21 Tanner R, Hahn A, Lawton E, et al. A comparison of physiological responses to ergometer and on-water racing. In: 5th IOC World Congress on Sport Sciences, Sydney, 1999:94.

22 Cohen J. Statistical power analysis for the behavioural sciences. Hillsdale, NJ: Lawrence Erlbaum Associates, 1988:25.

23 Ackland T, Kerr D, Hume P, et al. Anthropometric normative data for Olympic rowers and paddlers. In: Australian Conference of Science and Medicine in Sport. Perth: Sports Medicine Australia, 2001:157.

24 DeRose EH, Crawford SM, Kerr DA, et al. Physique characteristics of Pan American Games lightweight rowers. Int $J$ Sports Med 1989; 10:292-7.

25 Secher NH. Physiological and biomechanical aspects of rowing. Implications for training. Sports Med 1993;15:24-42.

26 Burge CM, Carey MF, Payne WR. Rowing performance, fluid balance, and metabolic function following dehydration and rehydration. Med Sci Sports Exerc 1993;25:1358-64.

27 Norton K, Hayward S, Charles S, et al. The effects of hypohydration and hyperhydration on skinfold measurements. In: Norton K, Olds T, Dollman J, eds. Sixth Scientific Conference of the International Society for the Advancement of Kinanthropometry. Vol VI. Adelaide: International Society for the Advancement of Kinanthropometry, 1998:253-66.

28 Lukaski HC. Estimation of muscle mass. In: Roche AF, Heymsfield SB Lohman TG, eds. Human body composition. Champaign, IL: Human Kinetics, 1996:109-28.

29 Thompson DL, Thompson WR, Prestridge TJ, et al. Effects of hydration and dehydration on body composition analysis: a comparative study of bioelectric impedance analysis and hydrodensitometry. I Sports Med Phys Fitness $1991 ; 31: 565-70$

30 Utter AC, Goss FL, Swan PD, et al. Evaluation of air displacement for assessing body composition of collegiate wrestlers. Med Sci Sports Exerc 2003;35:500-5. 